\title{
Current Limitations in Native Mass Spectrometry Based Structural Biology
}

\author{
Esther van Duijn \\ Biomolecular Mass Spectrometry and Proteomics Group, Bijvoet Center for Biomolecular Research and \\ Utrecht Institute for Pharmaceutical Sciences, Utrecht University, Utrecht, The Netherlands
}

\begin{abstract}
Nowadays, mass spectrometry plays an important role in structural biology. At one end it can be used to investigate intact protein complexes, providing details about the complex composition, topology, stability, and dynamics, whereas at the other end the protein's identity and possible modifications can be visualized using proteomics approaches. Combining all this information allows the generation of detailed models for functional biological assemblies. Here, a perspective on the application of native mass spectrometry in structural biology is presented. The potential of this technique and some important current limitations are discussed. This includes issues regarding the quality/homogeneity of the sample, the dissociation efficiency of protein complexes during tandem mass spectrometric analysis, and some boundaries of ion mobility mass spectrometry. (J Am Soc Mass Spectrom 2010, 21, 971-978) () 2010 American Society for Mass Spectrometry
\end{abstract}

$\mathrm{B}$ y all means mass spectrometry (MS) can be classified as one of the most rapidly evolving analytical tools of the last few decades. Regarding the analysis of proteins, it is now most renowned for its widespread applications in the field of proteomics. This is due in part to the increasing number of proteomic studies performed, and to extensive technological and instrumental developments, such as the invention of fast high-resolution mass analyzers, novel ionization techniques, and the introduction of stable isotope labeling approaches [1-7].

Equal and perhaps even more spectacular advances can be found within native MS. Native MS focuses on the structural and functional analysis of intact proteins and protein complexes [8]. In less than 30 years, the ability of measuring the mass of a peptide of $1000 \mathrm{Da}$ has shifted by five orders of magnitude, to the analysis of macromolecular complexes of more than 10 million Da [9-13]. In reviewing literature, notably one of the most commonly made statements is that native MS is becoming a powerful new structural biology technique. However, as evidenced by a vastly growing amount of reported studies, native MS is no longer only applied when the more traditional techniques, such as electron microscopy (EM), X-ray crystallography, and nuclear magnetic resonance (NMR), seem to have reached their limits or fail. Although native MS provides low-resolution structural information, it can surpass the other tools by its diversity in methodology and applications.

The assembly of proteins into a functional macromo-

Address reprint requests to Dr. E. van Duijn, Biomolecular MS and Proteomics Group, Utrecht University, Padualaan 8, $3584 \mathrm{CH}$ Utrecht, the Netherlands. E-mail: e.vanduijn1@uu.nl lecular complex remains one of the most mysterious processes in molecular life sciences. Already the smallest hitch in the assemblage can have a dramatic effect on its cellular activity [14, 15]. Many diseases are the result of incorrect protein folding that can hamper the binding of their cofactor and subsequently lead to nonspecific protein aggregation [16]. It is thus important to study these protein assemblies as intact entities. Native MS can reveal the composition, stoichiometry, dynamics, stability, and also the spatial arrangement of the subunits of protein assemblies. In combination with more proteomics based MS, i.e., profiling of post-translational modifications, complete pictures of intact biological machineries can be generated. At the same time, native MS is very sensitive and selective, allowing the analysis of even endogenous protein complexes [17-27]. Therefore, this technique should no longer be considered as a promising tool for structural biology. No, nowadays it has definitely proven to be a full-fledged member of the tool-box required to understand protein function at the cell machinery level.

As usual, the success stories have been well documented, and relatively less attention has been given to some of the remaining difficulties in native MS. Although this article is not meant to place it in a negative perspective, some examples will be given of where the technique is still in its infancy. Realizing what the current limits of native MS are will hopefully trigger further instrumental and methodological developments. Just as in the early days, when native MS was restricted to measuring masses only and tandem MS was introduced. Suddenly protein complexes could be dissected in the gas phase, giving information about their stability, structure, and topology [28]. More re- 
cently, ion mobility MS (IM-MS) was introduced, which allows to directly probe the cross-section (conformation) of protein complex ions in the gas phase $[29,30]$.

Independent of the approach chosen, above all the quality of the sample determines the outcome of the experiments. Native MS does not require large amounts of sample; a minimum of 10 picomoles is sufficient. Typically 100-500 pmol are desired to allow sample optimization and multiple analysis. However, native MS does put constraints on the sample purity/homogeneity. The influence of sample quality on the acquired mass spectra will be illustrated by the analysis of different macromolecular systems; a homomeric complex of gp16 from bacteriophage T4, the heteromeric complex between gp1 and gp4 from bacteriophage P22, and human hepatitis B virus capsids filled with small RNAs $[12,31]$. In recent years, gas-phase dissociation studies on macromolecular complexes have revealed that most complexes dissociate via a nearly generic decomposition pathway [32, 33]. However, this mechanism has also indicated some limitations in the use of tandem MS, especially when the complexes become very large and/or are not carrying many charges. The analysis of GroEL from Escherichia coli is used to show the current edge of tandem native MS. Alternative approaches are discussed that have recently gained popularity and may be used to (partly) overcome these issues. Finally, the current status of IM-MS in native MS is highlighted.

\section{Results and Discussion}

\section{Agree to Disagree}

For the majority of the complexes, the stoichiometry determined by native MS is in agreement with that revealed by other methods, although some exceptions have been described [34-37]. Chlorite dismutase from Azospira oryzae, an enzyme of the perchlorate and chlorate respiration system, was thought to assemble into tetramers as assessed by early ultracentrifugation experiments. However, the recently solved crystal structure of this enzyme revealed a hexameric organization, and subsequent native mass spectrometric analysis hinted at the sole presence of pentamers [37]. This might be an extreme example but clearly stresses that different methods do not always agree with each other. One possible explanation may be that depending on the technique, the protein is analyzed in quite different environments (crystal, solution, and gas phase).

Overall, it can be rather difficult to conclude which oligomeric state properly reflects the composition of the biologically active enzyme. Fortunately, the frequency of disagreeing results is outnumbered by cases where the various techniques are consistent $[8,12,22,29$, $38-40]$. Of course it can be questioned whether this is a proper reflection of the situation, or the consequence of the still consisting reluctance to report disagreeing results. Anyhow, this is a general dilemma in structural biology; not specifically stressing the limits of MS.

\section{Quality Rules}

In native MS, the quality of the sample is the primary determinant for success. As illustrated below, sample heterogeneity due to partial protein degradation or the binding of adducts can severely restrict the possibilities of this technique.

Figure 1a shows the mass spectrum for gp16, which is the small terminase protein of bacteriophage $\mathrm{T} 4$. Together with gp17, the large terminase protein, gp16 forms a holoenzyme complex of unknown stoichiometry and structure. The holoenzyme associates to the dodecameric portal protein gp20 to form the packaging motor of bacteriophage T4 [41]. There is great interest in revealing the biological activity of genome packaging systems in general, even by the pharmaceutical industry, as this may provide new entries to interfere with virus replication. So far, numerous packaging models have been proposed for bacteriophage T4 [42, 43], yet the basic details are still a mystery. Logically, a first start is elucidating the complex composition. More than a decade ago, scanning transmission electron microscopy measurements showed the formation of rings and side-by-side double rings for gp16 [44], estimated to consist of $8 \pm 3$ and $19 \pm 4$ monomers, respectively. Native MS analysis of gp16 indicated the presence of 11- and 22-mers, answering the long standing question of gp16's exact stoichiometry.

Unfortunately, both full-length and truncated gp16 (gp16 $\left.{ }_{9-164}\right)$ were present in this preparation, equally capable to oligomerize. This resulted in various compositions for the gp16 rings as indicated by the splitting of each charge state into multiple peaks. This was confirmed by creating a theoretical mass spectrum of undecameric gp16, composed of both gp16 and gp16 The spectra were in excellent agreement (Figure 1a, bottom panel) $[45,46]$. The highest $\mathrm{m} / \mathrm{z}$ value for each charge state corresponds to an undecamer solely composed of full length gp16, as established by tandem MS analysis (Figure 1a, inset). The adjacent peaks are the result of the successive exchange of one full length gp16 monomer for a gp16 ${ }_{9-164}$ monomer, up to six in total.

From this study, it might seem that sample heterogeneity does not complicate the analysis too much. However, the next step is to study gp16 in complex with gp17. Gp17 $(70 \mathrm{kDa})$ presumably forms pentamers, based on image processing and electron microscopy data [46]. When the mass and charge of a protein complex increases, it becomes more difficult to resolve individual peaks in the spectra. Thus, unfortunately, further MS analysis of the holoenzyme and packaging complex has not been successful.

A very similar observation in sample heterogeneity was made when investigating the first stages of tail assembly for bacteriophage P22 [31]. Whereas the mass spectrum of the gp1 portal complex showed a uniform distribution corresponding to a dodecamer, the addition of gp4 (first tail factor) resulted in peak splitting (Figure 1b). Analogous to what was described previ- 

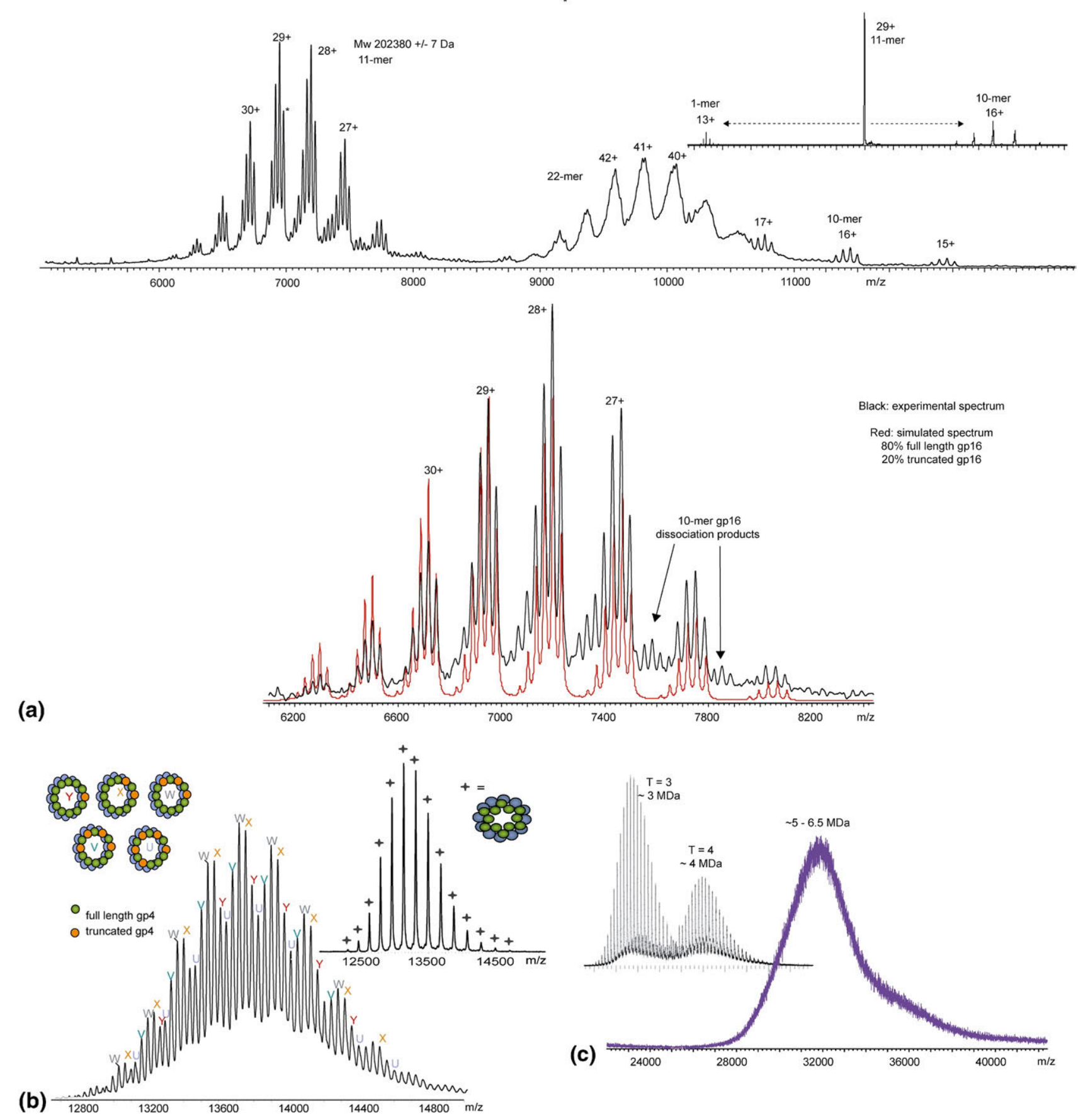

Figure 1. (a) Native mass spectrum of gp16 that forms 11- and 22-mers of 202,380 \pm 7 and $\sim 405,000 \mathrm{Da}$ (top). The low-charged 10-mers are the product of gas-phase dissociation. The highly charged monomers are not on this mass scale (around $2200 \mathrm{~m} / \mathrm{z}$ ). The peak indicated by an asterisk is selected for tandem MS (inset). The peak with the highest $m / z$ value for each charge state corresponds to a gp16 11-mer composed of full length gp16 only, as confirmed by the dissociation of a single species of gp16 with a mass of 18,389 \pm $1 \mathrm{Da}$. The bottom panel shows an overlay of the experimental mass spectrum of gp16 (black) and a simulated mass spectrum created by SOMMS (red) [45]. (b) Mass spectra of gp1 bound to gp4. Distributions of different gp1:gp4 complexes were present, originating from gp4 degradation. The inset shows a uniform complex between gp1 and gp4-142 $2^{\text {STOP }}$ (Figure adapted with permission [31]). (c) Mass spectra of HBV capsids formed by full length and truncated (inset) capsid proteins (Figure adapted with permission [12]).

ously, this originated from the partial degradation of gp4. Expression and purification of the truncated form of gp4 solely, and its complexation to the portal complex, resulted in a single distribution (Figure 1b).
A final example of how the heterogeneity of a sample can limit the success of MS comes from the analysis of intact human hepatitis B virus $T=3$ and $T=4$ capsids [12]. The monomeric building block is 183 amino acids 
long, of which the first 140 residues form the core domain. Via a linker region the core is connected to the C-terminal protamine domain which is involved in RNA binding, essential to package the genome at virus proliferation. During capsid production in Escherichia coli the capsids can unspecifically package small pieces of RNA from the host. As these small RNAs differ in size a heterogeneous mixture of filled capsids with slightly different masses is generated, impeding the resolution of individual charge states (Figure 1c). Deletion of the protamine domain (dispensable for capsid assembly), results into homogeneous capsids from which their accurate masses could be determined.

Clearly, complexes that differ only marginally in mass are extremely difficult to analyze by native MS because of overlapping charge states of the individual species. Similar phenomena are observed when proteins are sprayed from involatile buffers, such as Tris and Hepes, both extremely popular among biochemists for protein purification. These buffers are not easily compatible with native MS. The involatile substances will not fully evaporate during the electrospray ionization process, instead they will form adducts to the protein and suppress ionization. As the most generic compromise native mass spectrometric measurements are often performed using aqueous ammonium acetate at physiological pH as the "buffered" spray solution. On occasion, additional components are essential to keep noncovalent complexes intact in the gas phase. A complete overview of potential buffers and additives are described by Hernandez and Robinson [47], and more recently by Lorenzen and van Duijn [48].

In the category of intricate samples for MS, membrane protein complexes also need to be mentioned. Many membrane protein complexes cannot be purified to homogeneity and are problematic to study by structural biology techniques $[49,50]$. The major difficulty is that upon their removal from the physiologically relevant context, membrane proteins start to aggregate and may lose their function. Only recently it has come within reach to analyze these hydrophobic assemblies by native MS [51, 52]. The idea behind this success is to generate ions of complete micelles containing the membrane protein complex. By collisionally activating these ions, the micelle dissociates and ultimately leaves the "naked" protein complex for mass spectrometric analysis. The advantage of this method is that the membrane complexes retain their original oligomeric state $[51,52]$. However, a large amount of collisional activation energy is required to obtain the membrane protein complex by itself, leaving less space for subsequent studies regarding the topological arrangement of the subunits. Also, if the membrane protein is fully stripped, it is questionable to what extent the structure of the assembly is affected by the activation energy. On the contrary, if insufficient collisional activation is applied to the system, this results in incomplete stripping of the micelle (Supplementary material, which can be found in the electronic version of this article).

\section{Break Up to Decipher the Make Up}

Once the stoichiometry of a complex is determined, the next step is to probe the structural arrangement of the individual subunits. Often, this can be achieved by performing tandem MS (collision induced dissociation (CID), gas-phase dissociation). It is now well established that a greater part of all protein complexes follow a similar decomposition pathway, which may be used to study the structural arrangement of subunits $[32,53]$. In short, a protein complex ion is mass selected, and after its activation subunits will dissociate. Normally a small subunit, located at the periphery of the assembly, will dissociate preferentially. Before its release the charges of the protein complex ion relocate, whereby the majority of charges gather on the subunit to be expelled. The highly charged subunit unfolds and leaves the complex; a modestly charged stripped oligomer remains.

The dissociation efficiency of protein complex ions largely depends on their charge state, and is enhanced with increasing charge [33]. However, even for multiply charged protein complex ions breaking up is not always easy, due to the asymmetric distribution of charges upon dissociation. This is illustrated by the selection and activation of the 67+ ion of tetradecameric GroEL chaperonin (Figure 2a) [54]. The first monomer leaves the complex with $\sim 29$ charges ( $7 \%$ of the mass but $40 \%$ of the charge!). At higher activation energies a second monomer is released, taking about half the number of charges, leaving a dodecamer with an average of 19 charges. Dissociation of a third monomer is simply not possible because the number of residual charges is not sufficient. This means that the majority of the complex (often the core of the assembly) cannot be studied via this approach, and alternative methods have to be used to fully characterize the topology of macromolecular assemblies.

Recently, supercharging of ions were described to improve the gas-phase dissociation of protein complexes, as illustrated by Lomeli et al. for the $690 \mathrm{kDa} 20 \mathrm{~S}$ proteasome $[55,56]$. For GroEL, the average charge was increased from $66+$ to $71+$ after adding the supercharging compound m-nitrobenzyl alcohol (m-NBA) to the spray solution (Figure $2 \mathrm{~b}$ ). The highest charge state observed was $76+$ but, unfortunately, this was still not sufficient to expel a third subunit from the intact chaperonin (data not shown). Interestingly, the mass spectrum shows an increase in intensity of heptameric GroEL, which implies that the stability of the complex is affected by the addition of m-NBA. This is also important structural information as it reveals that the intact chaperone is formed by two heptameric rings stacked back-to-back together.

Nowadays, CID measurements are often preceded by in-solution dissociation of the protein complex. The addition of organic modifiers to the spray solution results in the formation of subcomplexes that reflect the stable entities of the assembly. The composition of each subcomplex is subsequently analyzed by CID. Combin- 
(a)

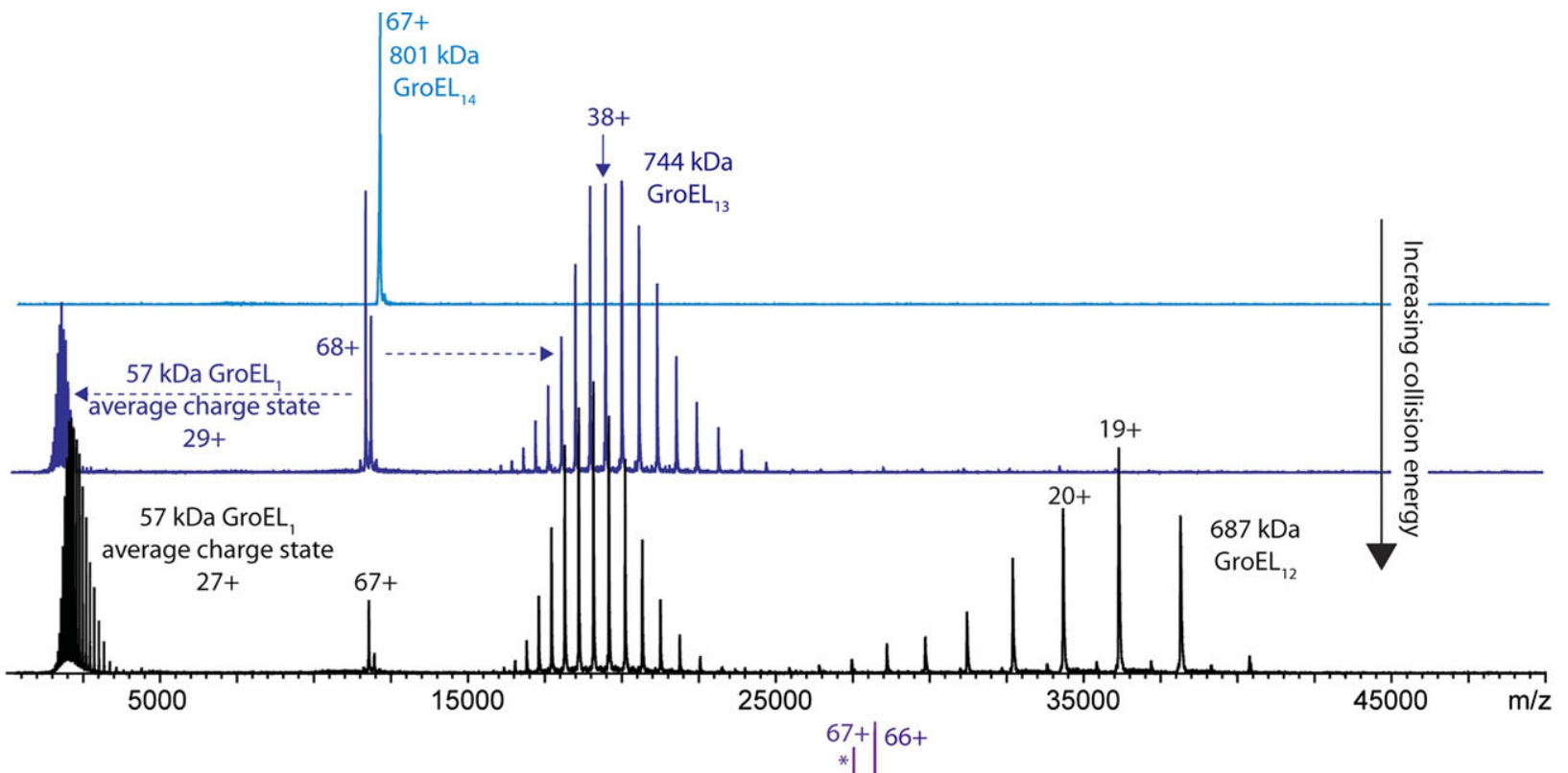

35000 $/ z$

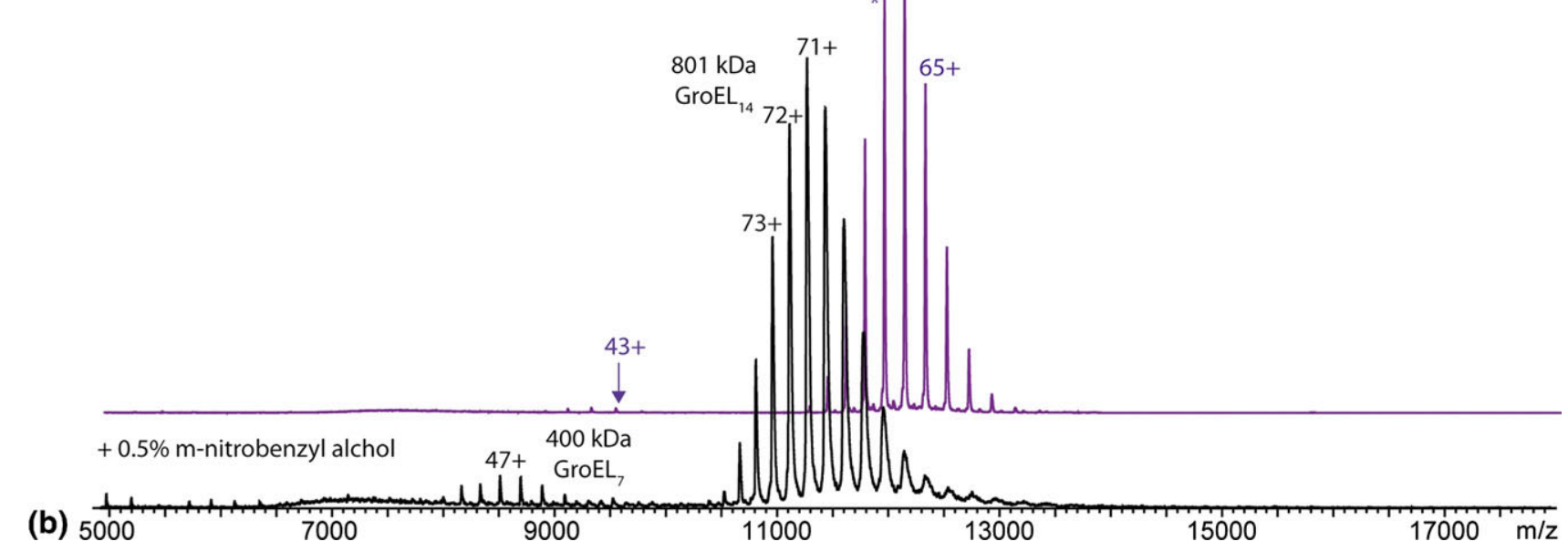

Figure 2. (a) Tandem mass spectra of $67+$ GroEL ions at varying collision energies. Without collisional activation, the GroEL chaperone remains intact (top panel, light blue). Upon increasing energies, first one monomer is released from the chaperon (middle panel, dark blue). At high collision energies (lower panel) up to two monomers can be expelled from the chaperonin, eventually leaving a $19+$ charged 12-mer of $687 \mathrm{kDa}$. (b) Native mass spectrum of GroEL sprayed from $50 \mathrm{mM}$ ammonium acetate pH 6.9 with (top, purple) and without (bottom, black) $0.5 \%$ m-nitrobenzyl alcohol. The addition of $\mathrm{m}-\mathrm{NBA}$ increases the number of charges on the chaperonin.

ing all gas-phase and in-solution dissociation data result in the generation of complete topology maps [19, $20,22,24,40,57]$.

What is clear is that the ideal candidate ion for tandem MS is highly charged. Whereas there are many methods that can reduce the charge of analyte ions, increasing their charge state is a far more challenging task [58-60]. Ion-ion reactions and collisions with molecular oxygen have been used to increase the ions' charge state; however, both have only been applied to peptides and small proteins.

Additionally, alternative dissociation approaches can also be considered, such as electron transfer- and electron capture dissociation (ETD and ECD). These methods are quickly gaining popularity in so-called "top-down" proteomics. Backbone fragment ions are formed from intact the protein, revealing their identity. While noncovalent bonds are likely preserved, ECD and ETD are less suitable to probe the topology of protein complexes. However, Xie et al. [61] elegantly showed the use of this method to identify protein-ligand interaction sites, which is normally quite a difficult task. Protein-ligand fragment ions were generated in which the noncovalent interactions were retained. In this way, direct information about the contact sites is obtained. To date, one of the largest proteins studied via a top-down MS approach was around $200 \mathrm{kDa}$ [62].

\section{Keep in Shape}

Most recently, ion mobility was coupled to native MS $[21,29,30,63]$. By IM-MS the mass, subunit composition 
and gas-phase conformation can be studied simultaneously. In a simplified way, one can state that the drift time of the ions, i.e., the time the ions require to drift through the gas-filled ion mobility chamber, depends on their collision cross section (conformation/shape).

To perform meaningful structural biology research, a fundamental criterion is that the structure of the protein complex resembles its active state. In vivo protein complexes are surrounded by cellular fluid, while in native MS the assemblies are studied in the gas phase. Often, native MS results indicated that the structure of protein complexes could be retained upon their transfer to the gas phase, but finally IM-MS could provide direct proof for this [64-66]. It should not come as a surprise, though, that the lower charge states best reflect the native structure of the protein complex [33, 65]. In contrast to tandem MS, IM-MS preferentially investigates low charged ions. The use of basic proton sponges have been described to reduce the net charge of protein assemblies [25, 67, 68]. Ion-ion reactions with anions or the use of a corona discharge particle source for proton transfer reactions can also reduce the ions' charge state $[59,69]$. These methods, however, concentrate on the analysis of peptides and small proteins.

Additionally, it is important to realize that at lower charge states protein complexes become more prone to bind adducts, compromising mass analysis. In addition, the efficiency of the time-of-flight detectors, normally used in native MS, significantly drops with increasing mass-to-charge values [70]. Also, the range of the TOF detector should be sufficiently high for the analysis of low charged protein complexes, which is currently $125,000 \mathrm{~m} / \mathrm{z}$ at maximum [53].

To date, the only commercial IM-MS instrument available in native MS is the Synapt from Waters (Milford, MA, USA). This mass spectrometer uses a traveling wave-type ion mobility chamber, thus calibration of the ion mobility cell is required, which is currently one of the major bottle-necks in native IM-MS $[30,71]$. There are only a handful of calibrant proteins available, with reported collision cross sections ranging from $1041 \AA^{2}$ up to $3815 \AA^{2}$ [72], clearly limiting high precision collision cross section determinations of very large protein complexes (typically $>100 \mathrm{~nm}^{2}$ ). A protocol for traveling wave IM-MS calibration has been described by Ruotolo et al. [21], allowing accurate and reproducible measurements [66]. Nonetheless, the precise determination of collision cross sections for very large protein complexes will greatly benefit by the availability of calibrant ions with large collision cross sections.

Another limitation of IM-MS on large biological complexes is the ion mobility resolution. This is important, especially when mixtures of large protein complexes, which differ only slightly in collision cross section, are present in the same spray solution. This year, Waters launched the second generation IM-MS instrument, the Synapt G2 that has significantly enhanced ion mobility resolution.

\section{Concluding Remarks}

At the beginning of this article, it was stated that native MS is no longer becoming a member in the field of structural biology, but by now has definitely found and deserved its place within. Just like any of the other methods, native MS is not always successful. The prime determinant for success is the quality of the sample, but perhaps no more so than for EM, NMR, or X-ray crystallography. Further methodological and technological developments, especially those regarding the process of protein charging, in solution dissociation, ion mobility cell calibration, and resolution, will fortify the position of native MS. Furthermore, the field of native MS will definitely benefit from instruments with higher sensitivity and selectivity. Such advances will not only allow the analysis of endogenous protein complexes to a more general basis, but will also enable the investigation of each protein complex individually in very complex samples.

Sometimes it may seem as if the different structural biology techniques are in competition with each other. However, it is far better to realize the strengths and weaknesses of each method separately and to combine their forces to claim the victory of solving the structure of a protein complex together. After all, isn't it much better to have two winners instead of two losers? This is exactly the current "trend" in structural biology, as more often MS results are integrated with structural data from various sources, leading to the generation of detailed structural models for protein complexes.

\section{Experimental}

Gp16 from bacteriophage T4 and GroEL from Escherichia coli, were purified as described previously [44, 73]. The buffers were exchanged to $50 \mathrm{mM}$ ammonium acetate $\mathrm{pH} 6.9$, using ultrafiltration units with a cutoff of 10,000 Da (Millipore, Bedford, MA, USA). Both gp16 and GroEL were analyzed at a concentration of $5 \mu \mathrm{M}$. To supercharge GroEL, m-nitrobenzyl alcohol was added to $0.5 \%$ (vol/vol). Electrospray ionization capillaries were prepared in house [53]. An LCT or a modified Q-ToF1 was used in positive ion mode (both Waters). Typically, mass spectra were recorded with a capillary voltage of $1.3 \mathrm{kV}$, cone voltage between $140-$ $200 \mathrm{~V}$, and a pressure of $\sim 7 \mathrm{mbar}$ in the source region. The collision cell of the Q-ToF1 was filled with Xenon and the collision voltage varied between $10-400 \mathrm{~V}$. The pressure in the ToF was $2.7 \times 10^{-6}$ mbar.

\section{Acknowledgments}

The author thanks Lindsay Black for providing gp16, Saskia van der Vies for her help in purifying GroEL, and Bas van Breukelen for the SOMMS simulations. Kristina Lorenzen, Charlotte Uetrecht, and Ioana Barbu are thanked for providing data for the figures. Shabaz Mohammed and Glen Shoemaker are thanked for critical reading. The author is grateful to Albert J. R. Heck for critical reading of the manuscript and overall support. The author 
acknowledges funding for this work by The Netherlands Organization for Scientific Research (NWO) (VENI 700.58.402 to E. van Duijn), and The Netherlands Proteomics Center.

\section{Appendix A Supplementary Material}

Supplementary material associated with this article may be found in the online version at doi:10.1016/j. jasms.2009.12.010.

\section{References}

1. Gygi, S. P.; Rist, B.; Gerber, S. A.; Turecek, F.; Gelb, M. H.; Aebersold, R. Quantitative Analysis of Complex Protein Mixtures using IsotopeCoded Affinity Tags. Nat. Biotechnol. 1999, 17, 994-999.

2. Heck, A. J.; Krijgsveld, J. Mass Spectrometry-Based Quantitative Proteomics. Expert Rev. Proteom. 2004, 1, 317-326.

3. Hu, Q.; Noll, R. J.; Li, H.; Makarov, A.; Hardman, M.; Graham Cooks, R. The Orbitrap: A New Mass Spectrometer. J. Mass Spectrom. 2005, 40, $430-443$.

4. Makarov, A. Electrostatic Axially Harmonic Orbital Trapping: A HighPerformance Technique of Mass Analysis. Anal. Chem. 2000, 72, 1156-1162.

5. Ong, S. E.; Blagoev, B.; Kratchmarova, I.; Kristensen, D. B.; Steen, H. Pandey, A.; Mann, M. Stable Isotope Labeling by Amino Acids in Cell Culture, SILAC, as a Simple and Accurate Approach to Expression Proteomics. Mol. Cell. Proteom. 2002, 1, 376-386.

6. Syka, J. E.; Marto, J. A.; Bai, D. L.; Horning, S.; Senko, M. W.; Schwartz, J. C.; Ueberheide, B.; Garcia, B.; Busby, S.; Muratore, T.; Shabanowitz, J.; Hunt, D. F. Novel Linear Quadrupole Ion trap/FT Mass Spectrometer: Performance Characterization and use in the Comparative Analysis of Histone H3 Post-Translational Modifications. J. Proteome Res. 2004, 3, 621-626.

7. Boersema, P. I.; Raijmakers, R.; Lemeer, S.; Mohammed, S.; Heck, A. J. Multiplex Peptide Stable Isotope Dimethyl Labeling for Quantitative Proteomics. Nat. Protoc. 2009, 4, 484-494.

8. van den Heuvel, R. H.; Heck, A. J. Native Protein Mass Spectrometry: From Intact Oligomers to Functional Machineries. Curr. Opin. Chem. Biol. 2004, 8, 519-526.

9. Kaddis, C. S.; Loo, J. A. Native Protein MS and Ion Mobility Large Flying Proteins with ESI. Anal. Chem. 2007, 79, 1778-1784.

10. Ganem, B.; Li, Y. T.; Henion, J. D. Detection of Noncovalent ReceptorLigand Complexes by Mass Spectrometry. J. Am. Chem. Soc. 1991, 113, 6294-6296.

11. Videler, H.; Ilag, L. L.; McKay, A. R.; Hanson, C. L.; Robinson, C. V. Mass Spectrometry of Intact Ribosomes. FEBS Lett. 2005, 579, 943-947.

12. Uetrecht, C.; Versluis, C.; Watts, N. R.; Roos, G. J. L.; Wingfield, P. T.; Steven, A. C.; Heck, A. J. High Resolution Mass Spectrometry of Viral Assemblies: Molecular Composition and Stability of Dimorphic Hepatitis B Virus Capsids. Proc. Natl. Acad. Sci. U.S.A. 2008, 105, 9216-9220.

13. van Duijn, E.; Barendregt, A.; Uetrecht, C.; Lorenzen, K.; Rose, R. J.; Shoemaker, G.; Heck, A. J. Investigation of Intact Protein Complexes and Protein-Protein Interactions by Native Ion Mobility and Tandem Mass Spectrometry. Proceedings of the 57th ASMS Conference; Philadelphia, May 31-June 4, 2009.

14. Hartl, F. U.; Hayer-Hartl, M. Molecular Chaperones in the Cytosol: From Nascent Chain to Folded Protein. Science 2002, 295, 1852-1858.

15. Hartl, F. U.; Hayer-Hartl, M. Converging Concepts of Protein Folding In Vitro and In Vivo. Nat. Struct. Mol. Biol. 2009, 16, 574-581.

16. Ross, C. A.; Poirier, M. A. Protein Aggregation and Neurodegenerative Disease. Nat. Med. 2004, 10(Suppl.), 10-17.

17. Benesch, J. L.; Ruotolo, B. T.; Simmons, D. A.; Robinson, C. V. Protein Complexes in the Gas Phase: Technology for Structural Genomics and Proteomics. Chem. Rev. 2007, 107, 3544-3567.

18. Heck, A. J.; Van Den Heuvel, R. H. Investigation of Intact Protein Complexes by Mass Spectrometry. Mass Spectrom Rev. 2004, 23, 368-389.

19. Heck, A. J. Native Mass Spectrometry: A Bridge Between Interactomics and Structural Biology. Nat. Methods 2008, 5, 927-933.

20. Lorenzen, K.; Vannini, A.; Cramer, P.; Heck, A. J. Structural Biology of RNA Polymerase III: Mass Spectrometry Elucidates Subcomplex Architecture. Structure 2007, 15, 1237-1245.

21. Ruotolo, B. T.; Benesch, J. L.; Sandercock, A. M.; Hyung, S. J.; Robinson, C. V. Ion Mobility-Mass Spectrometry Analysis of Large Protein Complexes. Nat. Protoc. 2008, 3, 1139-1152.

22. Sharon, M.; Robinson, C. V. The Role of Mass Spectrometry in Structure Elucidation of Dynamic Protein Complexes. Annu. Rev. Biochem. 2007, 76, 167-193.

23. Sharon, M.; Mao, H.; Boeri Erba, E.; Stephens, E.; Zheng, N.; Robinson, C. V. Symmetrical Modularity of the COP9 Signalosome Complex Suggests Its Multifunctionality. Structure 2009, 17, 31-40.

24. Taverner, T.; Hernandez, H.; Sharon, M.; Ruotolo, B. T.; Matak-Vinkovic, D.; Devos, D.; Russell, R. B.; Robinson, C. V. Subunit Architecture of Intact Protein Complexes from Mass Spectrometry and Homology Modeling. Acc. Chem. Res. 2008, 41, 617-627.
25. van Duijn, E.; Barendregt, A.; Synowsky, S.; Versluis, C.; Heck, A. J. Chaperonin Complexes Monitored by Ion Mobility Mass Spectrometry. J. Am. Chem. Soc. 2009, 131, 1452-1459.

26. Robinson, C. V.; Sali, A.; Baumeister, W. The Molecular Sociology of the Cell. Nature 2007, 450, 973-982

27. Mohammed, S.; Lorenzen, K.; Kerkhoven, R.; van Breukelen, B.; Vannini, A.; Cramer, P.; Heck, A. J. Multiplexed Proteomics Mapping of Yeast RNA Polymerase II and III Allows Near-Complete Sequence Coverage and Reveals several Novel Phosphorylation Sites. Anal. Chem. 2008, 80, 3584-3592.

28. Sobott, F.; Hernandez, H.; McCammon, M. G.; Tito, M. A.; Robinson, C. V. A Tandem Mass Spectrometer for Improved Transmission and Analysis of Large Macromolecular Assemblies. Anal. Chem. 2002, 74, 1402-1407.

29. Ruotolo, B. T.; Giles, K.; Campuzano, I.; Sandercock, A. M.; Bateman, R. H.; Robinson, C. V. Evidence for Macromolecular Protein Rings in the Absence of Bulk Water. Science 2005, 310, 1658-1661.

30. Pringle, S. D.; Giles, K.; Wildgoose, J. L.; Williams, J. P.; Slade, S. E.; Thalassinos, K.; Bateman, R. H.; Bowers, M. T.; Scrivens, J. H. An Investigation of the Mobility Separation of Some Peptide and Protein Ions using a New Hybrid Quadrupole/Traveling Wave IMS/oa-TOF Instrument. Int. J. Mass Spectrom. 2007, 261, 1-12.

31. Lorenzen, K.; Olia, A. S.; Uetrecht, C.; Cingolani, G.; Heck, A. J. Determination of Stoichiometry and Conformational Changes in the First Step of the P22 Tail Assembly. J. Mol. Biol. 2008, 379, 385-396.

32. Benesch, J. L.; Aquilina, J. A.; Ruotolo, B. T.; Sobott, F.; Robinson, C. V. Tandem Mass Spectrometry Reveals the Quaternary Organization of Macromolecular Assemblies. Chem. Biol. 2006, 13, 597-605.

33. Benesch, J. L. Collisional Activation of Protein Complexes: Picking Up the Pieces. J. Am. Soc. Mass Spectrom. 2009, 20, 341-348.

34. Benesch, J. L.; Ayoub, M.; Robinson, C. V.; Aquilina, J. A. Small Hea Shock Protein Activity is Regulated by Variable Oligomeric Substructure. J. Biol. Chem. 2008, 283, 28513-28517.

35. McCammon, M. G.; Scott, D. J.; Keetch, C. A.; Greene, L. H.; Purkey H. E.; Petrassi, H. M.; Kelly, J. W.; Robinson, C. V. Screening Transthyretin Amyloid Fibril Inhibitors: Characterization of Novel Multiprotein, Multiligand Complexes by Mass Spectrometry. Structure 2002, 10, 851-863.

36. Poliakov, A.; van Duijn, E.; Lander, G.; Fu, C. Y.; Johnson, J. E.; Prevelige, P. E., Jr; Heck, A. J. Macromolecular Mass Spectrometry and Electron Microscopy as Complementary Tools for Investigation of the Heterogeneity of Bacteriophage Portal Assemblies. J. Struct. Biol. 2007 $157,371-383$

37. de Geus, D. C.; Thomassen, E. A.; Hagedoorn, P. L.; Pannu, N. S.; van Duijn, E.; Abrahams, J. P. Crystal Structure of Chlorite Dismutase, a Detoxifying Enzyme Producing Molecular Oxygen. J. Mol. Biol. 2009, 387, 192-206.

38. Loo, J. A.; Berhane, B.; Kaddis, C. S.; Wooding, K. M.; Xie, Y.; Kaufman, S. L.; Chernushevich, I. V. Electrospray Ionization Mass Spectrometry and Ion Mobility Analysis of the 20S Proteasome Complex. J. Am. Soc. Mass Spectrom. 2005, 16, 998-1008.

39. van Duijn, E.; Bakkes, P. J.; Heeren, R. M.; van den Heuvel, R. H.; van Heerikhuizen, H.; van der Vies, S. M.; Heck, A. J. Monitoring Macromolecular Complexes Involved in the Chaperonin-Assisted Protein Folding Cycle by Mass Spectrometry. Nat. Methods 2005, 2, 371-376.

40. Zhou, M.; Sandercock, A. M.; Fraser, C. S.; Ridlova, G.; Stephens, E Schenauer, M. R.; Yokoi-Fong, T.; Barsky, D.; Leary, J. A.; Hershey, J. W.; Doudna, J. A.; Robinson, C. V. Mass Spectrometry Reveals Modularity and a Complete Subunit Interaction Map of the Eukaryotic Translation Factor eIF3. Proc. Natl. Acad. Sci. U.S.A. 2008, 105, 18139-18144.

41. Black, L. W. DNA Packaging in dsDNA Bacteriophages. Annual Review of Microbiology. 1989, 43, 267-292.

42. Mitchell, M. S.; Rao, V. B. Functional Analysis of the Bacteriophage T4 DNA-Packaging ATPase Motor. The J. Biol. Chem. 2006, 281, 518-527.

43. Williams, R. S.; Williams, G. J.; Tainer, J. A. A Charged Performance by gp17 in Viral Packaging. Cell 2008, 135, 1169-1171.

44. Lin, H.; Simon, M. N.; Black, L. W. Purification and Characterization of the Small Subunit of Phage T4 Terminase, gp16, Required for DNA Packaging. J. Biol. Chem. 1997, 272, 3495-3501.

45. van Breukelen, B.; Barendregt, A.; Heck, A. J.; van den Heuvel, R. H. Resolving Stoichiometries and Oligomeric States of Glutamate Synthase Protein Complexes with Curve Fitting and Simulation of Electrospray Mass Spectra. Rapid Commun. Mass Spectrom. 2006, 20, 2490-2496.

46. Sun, S.; Kondabagil, K.; Draper, B.; Alam, T. I.; Bowman, V. D.; Zhang, Z.; Hegde, S.; Fokine, A.; Rossmann, M. G.; Rao, V. B. The Structure of the Phage T4 DNA Packaging Motor Suggests a Mechanism Dependent on Electrostatic Forces. Cell 2008, 135, 1251-1262.

47. Hernandez, H.; Robinson, C. V. Determining the Stoichiometry and Interactions of Macromolecular Assemblies from Mass Spectrometry. Nat. Protoc. 2007, 2, 715-726.

48. Lorenzen, K.; van Duijn, E. Native Mass Spectrometry as a Tool in Structural Biology. Curr. Protoc. Protein Sci. accepted.

49. Bartesaghi, A.; Subramaniam, S. Membrane Protein Structure Determination using Cryo-Electron Tomography and 3D Image Averaging. Curr. Opin. Struct. Biol. 2009, 19, 402-407.

50. Raunser, S.; Walz, T. Electron Crystallography as a Technique to Study the Structure on Membrane Proteins in a Lipidic Environment. Annu. Rev. Biophys. 2009, 38, 89-105.

51. Barrera, N. P.; Isaacson, S. C.; Zhou, M.; Bavro, V. N.; Welch, A. Schaedler, T. A.; Seeger, M. A.; Miguel, R. N.; Korkhov, V. M.; van Veen, 
H. W.; Venter, H.; Walmsley, A. R.; Tate, C. G.; Robinson, C. V. Mass Spectrometry of Membrane Transporters Reveals Subunit Stoichiometry and Interactions. Nat. Methods 2009, 6, 585-587.

52. Barrera, N. P.; Di Bartolo, N.; Booth, P. J.; Robinson, C. V. Micelles Protect Membrane Complexes from Solution to Vacuum. Science 2008, 321, 243-246.

53. van den Heuvel, R. H.; van Duijn, E.; Mazon, H.; Synowsky, S. A.; Lorenzen, K.; Versluis, C.; Brouns, S. J.; Langridge, D.; van der Oost, J.; Hoyes, J.; Heck, A. J. Improving the Performance of a Quadrupole Time-of-Flight Instrument for Macromolecular Mass Spectrometry. Anal. Chem. 2006, 78, 7473-7483.

54. van Duijn, E.: Simmons, D. A.; van den Heuvel, R. H.; Bakkes, P. J.; van Heerikhuizen, H.; Heeren, R. M.; Robinson, C. V.; van der Vies, S. M.; Heck, A. J. Tandem Mass Spectrometry of Intact GroEL-Substrate Complexes Reveals Substrate-Specific Conformational Changes in the Trans Ring. J. Am. Chem. Soc. 2006, 128, 4694-4702.

55. Lomeli, S. H.; Yin, S.; Ogorzalek Loo, R. R.; Loo, J. A. Increasing Charge While Preserving Noncovalent Protein Complexes for ESI-MS. J. Am. Soc. Mass Spectrom. 2009, 20, 593-596.

56. Lomeli, S. H.; Peng, I. X.; Yin, S.; Loo, R. R. O.; Loo, J. A. New Reagents for Increasing ESI Multiple Charging of Proteins and Protein Complexes. J. Am. Soc. Mass Spectrom. 2010, 21, 126-131.

57. Pukala, T. L.; Ruotolo, B. T.; Zhou, M.; Politis, A.; Stefanescu, R.; Leary, J. A.; Robinson, C. V. Subunit Architecture of Multiprotein Assemblies Determined Using Restraints from Gas-Phase Measurements. Structure 2009, 17, 1235-1243.

58. Smith, L. M. Is Charge Reduction in ESI really Necessary? J. Am. Soc. Mass Spectrom. 2008, 19, 629-631.

59. Frey, B. L.; Krusemark, C. J.; Ledvina, A. R.; Coon, J. J.; Belshaw, P. J.; Smith, L. M. Ion-Ion Reactions with Fixed-Charge Modified Proteins to Produce Ions in a Single, Very High Charge State. Int. J. Mass Spectrom. 2008, 276, 136-143.

60. Pitteri, S. J.; McLuckey, S. A. Recent Developments in the Ion/Ion Chemistry of High-Mass Multiply Charged Ions. Mass Spectrom. Rev. 2005, 24, 931-958.

61. Xie, Y.; Zhang, J.; Yin, S.; Loo, J. A. Top-Down ESI-ECD-FT-ICR Mass Spectrometry Localizes Noncovalent Protein-Ligand Binding Sites. J. Am. Chem. Soc. 2006, 128, 14432-14433.
62. Breuker, K.; Jin, M.; Han, X.; Jiang, H.; McLafferty, F. W. Top-Down Identification and Characterization of Biomolecules by Mass Spectrometry. J. Am. Soc. Mass Spectrom. 2008, 19, 1045-1053.

63. Uetrecht, C., Rose, R. J., van Duijn, E., Lorenzen, K., Heck, A. J. Ion Mobility Mass Spectrometry of Proteins and Protein Assemblies. Chem. Soc. Rev. in press.

64. Liu, L.; Bagal, D.; Kitova, E. N.; Schnier, P. D.; Klassen, J. S. Hydrophobic Protein-Ligand Interactions Preserved in the Gas Phase. J. Am. Chem. Soc. 2009, 131, 15980-15981.

65. Ruotolo, B. T.; Hyung, S. J.; Robinson, P. M.; Giles, K.; Bateman, R. H. Robinson, C. V. Ion Mobility-Mass Spectrometry Reveals Long-Lived, Unfolded Intermediates in the Dissociation of Protein Complexes. Angew. Chem. Int. Ed. 2007, 46, 8001-8004.

66. Uetrecht, C.; Versluis, C.; Watts, N. R.; Wingfield, P. T.; Steven, A. C. Heck, A. J. Stability and Shape of Hepatitis B Virus Capsids In Vacuo. Angew. Chem. Int. Ed. Engl. 2008, 47, 6247-6251.

67. Catalina, M. I.; van den Heuvel, R. H.; van Duijn, E.; Heck, A. J Decharging of Globular Proteins and Protein Complexes in Electrospray. Chemistry 2005, 11, 960-968.

68. Sun, J.; Kitova, E. N.; Klassen, J. S. Method for Stabilizing ProteinLigand Complexes in Nanoelectrospray Ionization Mass Spectrometry. Anal. Chem. 2007, 79, 416-425.

69. Ebeling, D. D.; Westphall, M. S.; Scalf, M.; Smith, L. M. Corona Discharge in Charge Reduction Electrospray Mass Spectrometry. Anal. Chem. 2000, 72, 5158-5161.

70. Chen, X.; Westphall, M. S.; Smith, L. M. Mass Spectrometric Analysis of DNA Mixtures: Instrumental Effects Responsible for Decreased Sensitivity with Increasing Mass. Anal. Chem. 2003, 75, 5944-5952.

71. Giles, K.; Pringle, S. D.; Worthington, K. R.; Little, D.; Wildgoose, J. L.; Bateman, R. H. Applications of a Traveling Wave-Based Radio-FrequencyOnly Stacked Ring Ion Guide. Rapid Commun. Mass Spectrom. 2004, 18 , 2401-2414.

72. Clemmer Cross Section Database. Http://www.Indiana.edu/ clemmer.

73. Bakkes, P. J.; Faber, B. W.; van Heerikhuizen, H.; van der Vies, S. M. The T4-Encoded Cochaperonin, gp31, Has Unique Properties that Explain Its Requirement for the Folding of the T4 Major Capsid Protein. Proc. Natl. Acad. Sci. U.S.A. 2005, 102, 8144-8149. 